\title{
A study of the solid earth tides, ocean and atmospheric loadings using an 8-year record (2010-2018) from superconducting gravimeter OSG-060 at Djougou (Benin, West
} Africa)

\author{
Jacques Hinderer $*$, U. Riccardi , S. Rosat, J.-P. Boy , B. Hector , M. Calvo, F. L Littel, J.-D. Bernard \\ IPGS/EOST, 5 rue Descartes, France
}

\begin{abstract}
A B S T R A C T
We investigate a nearly 8-year record (2010-2018) of the superconducting gravimeter OSG-060 located at Djougou (Benin, West Africa). We first perform a tidal analysis with ET34-ANA v7.1 software that leads to the gravimetric amplitude and phase factors for all separable waves according to the available time duration. We test nine different ocean tide models for the main eleven tidal constituents (Ssa, Mm, Mf, Q1, O1, P1, K1, N2, M2, S2, K2). After correction for ocean tidal loading we obtain the real and imaginary parts of the residual vector. We also investigate atmospheric loading which is dominated in this equatorial location by the thermal waves S1 and S2 that are modulated in amplitude by annual and semi-annual components. After correction for ocean loading, we test different air pressure corrections on the tidal gravimetric factors for the waves Sa, Ssa, S1 and S2. We show the rather large discrepancy that exists between the classical single admittance pressure reduction and a hybrid model using global atmospheric models everywhere except in the local zone where the model pressure is replaced by the observed pressure.
\end{abstract}

\section{Introduction}

The superconducting gravimeter OSG-060 from GWR Instruments has been installed in Nalohou, close to Djougou in northern Benin (West Africa) in July 2010. This installation was done in the frame of the GHYRAF (Gravity and Hydrology in Africa) program that lasted from 2008 to 2012 (Hinderer et al., 2012). This gravimeter is part of the IGETS (International Geodynamics and Earth Tides Service) under the umbrella of IAG (International Association of Geodesy). Fig. 1 shows the location of the Djougou station (The geographical coordinates of the station are $9.7424^{\circ} \mathrm{N}$ and $1.6056^{\circ} \mathrm{E}$ ) among the other stations of the international network of superconducting gravimeters (SG).

It is noticeable that only two stations exist in Africa (Djougou in Benin and Sutherland in South Africa) and, even more important, Djougou is the only equatorial station of the network to date since the end of operation of the Bandung and Cibinong stations in Indonesia. This means that Djougou station is especially valuable for studying the Earth's lunisolar tides, as well as the ocean tidal loading and atmospheric loading.
Before the installation of the SG, since no power was available, a $1.5 \mathrm{~km}$ line of medium voltage was first set up. Then several buildings shown on Fig. 2 were built with the generator building at a sufficiently large distance from the two buildings dedicated to the SG and the absolute gravimeter (AG) that episodically measures in parallel with the SG. The generators (one main + two spare equipments) turned out to be vital because of the numerous power shortages that range from a few hours to 15 days occurring in Djougou.

The choice of this location for installing the SG was driven by the fact that Nalohou is part of the Ara catchment, one of the key sites in the Sudanian region monitored by AMMA-CATCH hydrological and meteorological observatory (http://www.amma-catch.org/) with a high density of data available over a long time span of several decades.

\section{Gravity data processing}

The first results in terms of calibration and instrumental drift of OSG-060 have been reported by Hinderer et al. (2014a) for a period ranging from July 2010 to May 2011.

\footnotetext{
* Corresponding author.

Email address: jhinderer@unistra.fr (J. Hinderer)
} 

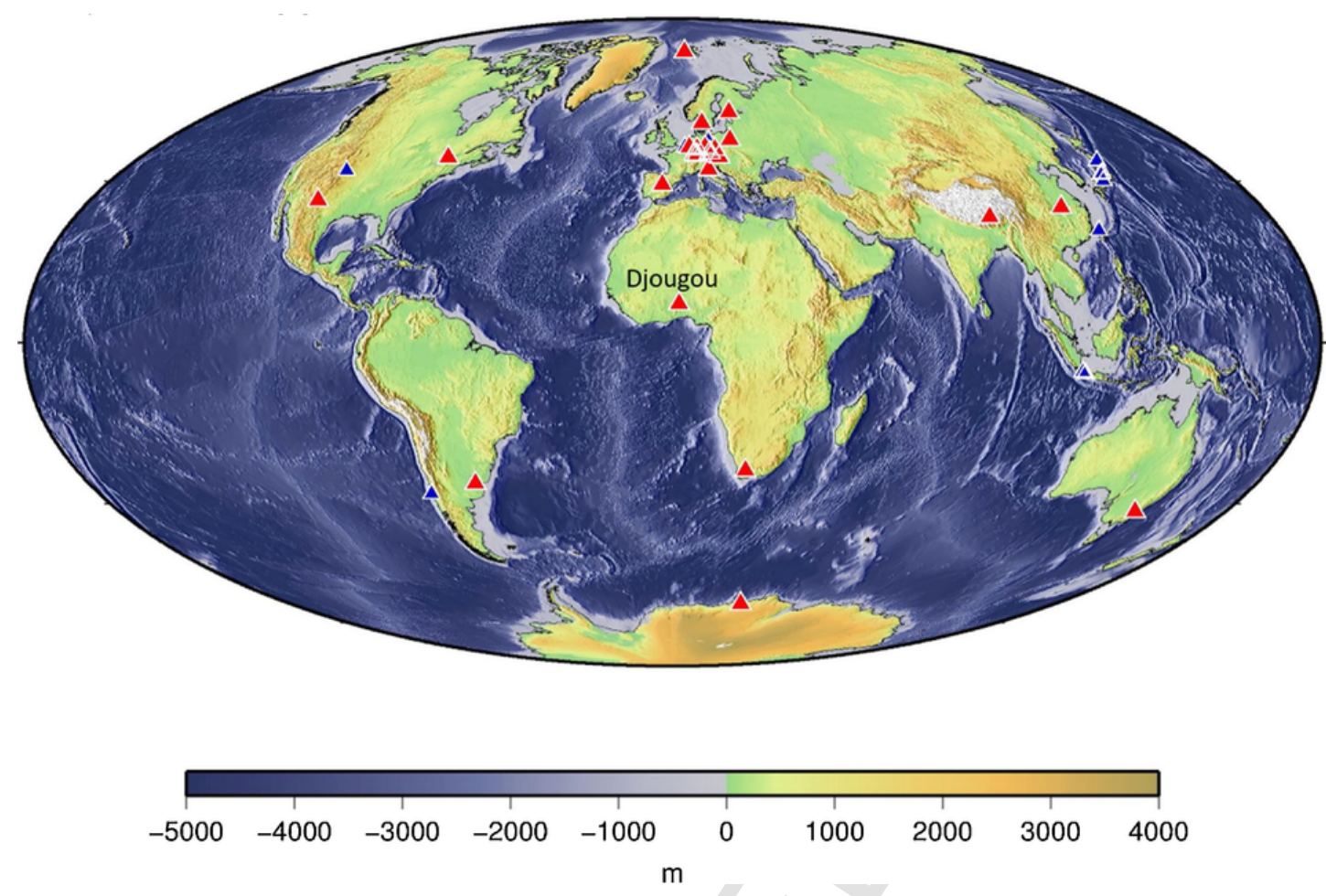

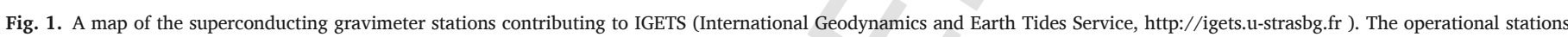
in 2018 are in red and former stations now stopped are in blue.

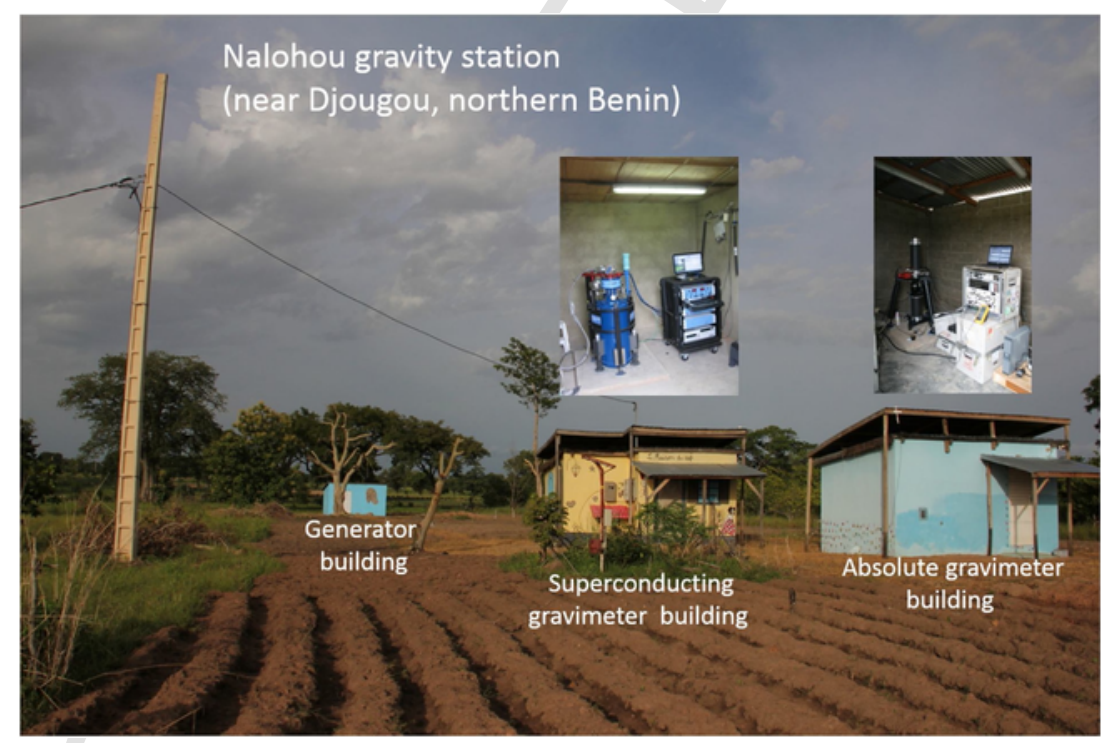

Fig. 2. A picture of the three buildings belonging to the Djougou gravity station in Nalohou.

The scale factor of OSG-060 was obtained from a parallel registration of 5 days (8-15 April 2011) with an absolute gravimeter FG5\#206 which is the classical way to calibrate SGs (e.g. Hinderer et al., 1991; Imanishi et al., 2002). For a detailed discussion on various aspects of the AG/SG calibration, we refer to the recent studies by Riccardi et al. (2012) and Crossley et al. (2018).

We used a least square fit of the SG values to AG drop values every $10 \mathrm{~s}$ (second) yielding a value of $-709 \pm 4 \mathrm{~nm} \mathrm{~s}^{-2} /$ volt (precision of $5.6 \%$ ).

The phase experiment to determine the phase shift of the instrument (sensor + decimation filter) was done in July 2012 using the step method (Wenzel, 1991) and led to a time delay of $10.6 \pm 0.1 \mathrm{~s}$.
The SG-060 gravity and air pressure data are sampled at both 1 and $60 \mathrm{~s}$. As done classically, the gravity record is corrected for the major disturbances resulting in spikes, steps or gaps.

Some of these disturbances are caused by earthquakes (saturation of the sensor due to the arrival of seismic waves) or are man-made (in the case of instrumental maintenance for instance). We refer the reader to Hinderer et al. (2002) and Hinderer et al. (2015) for more details on the processing steps.

The cleaned pressure and gravity data sets are shown on Fig. 3 for the investigated period (2010-2018). The correction for lunisolar tides (solid Earth + ocean tidal loading), as well as for atmospheric effects and Earth's rotation leads to the gravity residuals (in black on Fig. 4). 

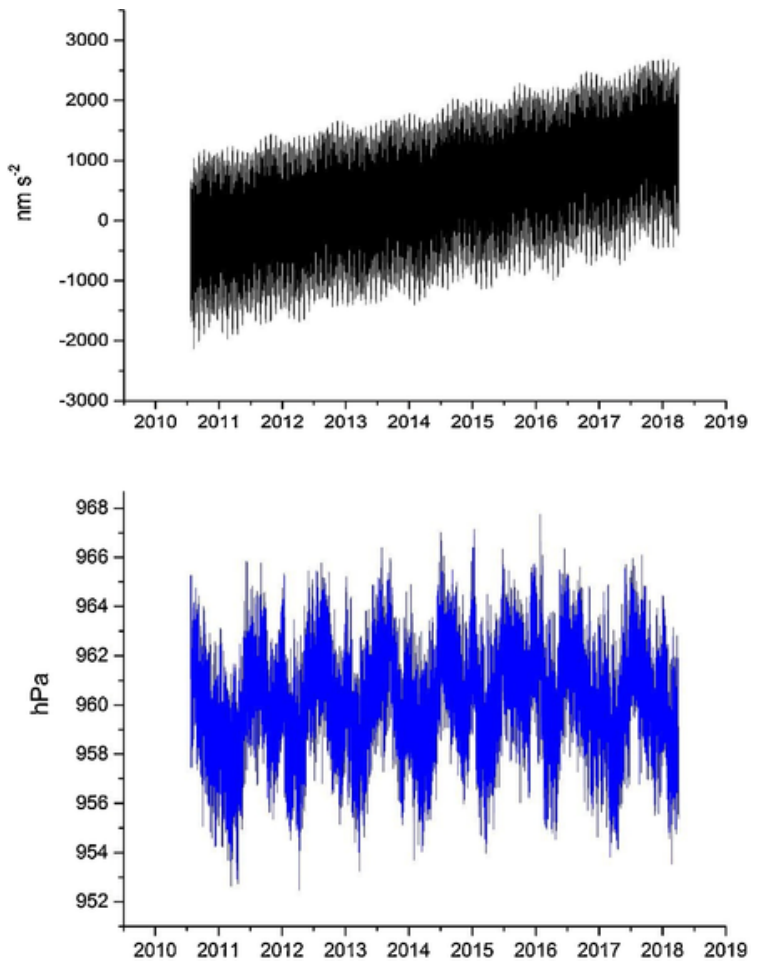

Fig. 3. Gravity (in $\mathrm{nm} \mathrm{s}^{-2}$ ) and barometric pressure (in $\mathrm{hPa}$ ) recorded at the Djougou station from 2010 to 2018.

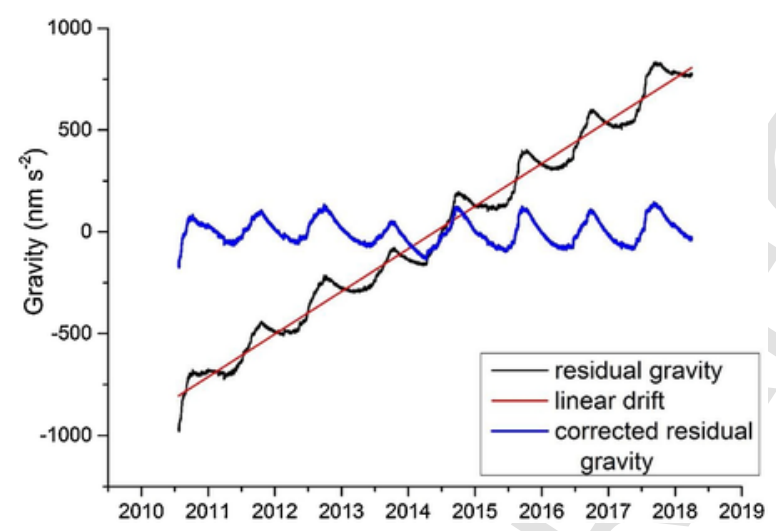

Fig. 4. Residual gravity signal (in $\mathrm{nm} \mathrm{s}^{-2}$ ) (in black) after correction for solid Earth and ocean tidal loading, atmospheric effects and Earth's rotation; corrected gravity residuals (in blue) after subtracting a linear instrumental drift (in red).

A further correction for the instrumental drift of the gravimeter (in red on Fig. 4) leads then to the corrected residual signal (in blue on Fig. 4) that is merely of hydrological origin and characterized by an annual periodicity (see Boy and Hinderer 2006; Hector et al., 2014).

The instrumental drift is composed of an initial exponential term followed by a linear term that remains stable over the years. This is very classical for SGs and confirms the earlier results based on a 1.5 year record (Hinderer et al., 2014a, 2014b).

The fit to an exponential function $\mathrm{g}=\mathrm{g} 0+\mathrm{A} 1 * \exp (-(\mathrm{x}-\mathrm{x} 0) / \mathrm{T} 1)$, where $\mathrm{g} 0$ and $\mathrm{x} 0$ are the starting values of gravity and time, leads to an amplitude $\mathrm{A} 1$ of $-147.6 \pm 1.2 \mathrm{~nm} \mathrm{~s}^{-2}$ and a time delay $\mathrm{T} 1=13.8 \pm 0.3$ days. It must be noted that this exponential drift had to be done on the residual gravity corrected for hydrological loading which mixes up with the instrumental part.

In our case, we used MERRA2 global hydrology model (Reichle et al., 2017) available at the EOST loading service (http://loading.u- strasbg.fr). The linear drift is $+213.6 \pm 0.1 \mathrm{~nm} \mathrm{~s} \mathrm{~s}^{-2} /$ year, which is rather large for SGs (Hinderer et al., 2015), but the linearity is very strong and apparently stable in time from our tests.

\section{Tidal analysis and ocean tidal loading}

We analyze the whole dataset of gravity records (nearly 8 years), using the Hartmann and Wenzel (1995) tidal potential catalogue. Amplitude and phase tidal parameters (Fig. 5) for groups combining inseparable constituents as well as the air pressure admittance factors are adjusted in the long period, diurnal and sub-diurnal frequency bands by means of ET34-ANA v7.1 software (Schüller, 2018); the complete list of the adjusted tidal parameters is given in Annex A.

From the free Ocean Tide Loading Provider (Bos \& Scherneck 2019) we retrieve the time invariant loading contribution to reduce the ocean loading effect in the collected gravity records. The computed contributions are resulting from nine different global ocean tide models: GOT00.2 (Ray, 1999), GOT4.7 (update of Ray, 1999), TPXO8 (Egbert and Erofeeva, 2002), FES2004 (Lyard et al., 2006), FES2014b (Carrère et al., 2015), OSU12 (Fok, 2012), DTU10 (Cheng and Andersen, 2010), HAMTIDE (Taguchi et al., 2014) and NAO99 (Matsumoto et al., 2000).

Finally, we calculate the corrected tidal parameters for the main eleven tidal constituents (Ssa, Mm, Mf, Q1, O1, P1, K1, N2, M2, S2, K2) by averaging the results of the nine ocean models to tackle the inaccuracies rising from the limited spatial resolution of the models which might be relevant especially at locations in coastal areas (e.g. Habel and Meurers, 2014) (Fig. 6a, b).

It is noteworthy that ocean loading residual vectors can be used to get insight into calibration inaccuracies of gravimeters, both in amplitude and phase. Since the observed phase lags of the tidal parameters are routinely small (in the order of few degrees), inaccuracies in the calibration constants will map only on the real part (in-phase) of the residual vector. On the contrary, an inaccurate phase determination in the gravity observations, due for instance to a wrong filter delay or even a missing or inaccurate phase calibration, will only appear in the imaginary part (out-of-phase).

In addition to the main gravitational tidal waves, other tidal components are provided in the FES2014b model, including the diurnal S1 tide forced by air pressure. This allows testing the effect of ocean loading correction on the retrieval of solar tidal waves and related air pressure ones in the equatorial band (Fig. 11).

Except for S2 tide, where all ocean models exhibit large in-phase and out-of-phase components, all the other results mostly show a cluster around $(0,0)$. There is no significant systematic deviation in the in-phase component that would imply a calibration error or in the out-of-phase component related to a time delay error.

\section{Free Core Nutation resonance in diurnal frequency band}

Because of the existence of a slightly elliptical fluid core, the Earth possesses a normal mode called Free Core Nutation (FCN), which consists of a free wobble of the fluid Core around the Earth's rotation axis, with fluid pressure acting as a feedback mechanism. In a rotating terrestrial frame attached to the Earth's mantle, the FCN has a quasi-diurnal period but is retrograde with a 430-day period in an inertial frame. Under the forcing by tides at diurnal periods, we can observe a resonance effect in the Earth's gravimetric response. The FCN resonance effect has been widely studied in surface gravimetric observations (Neuberg et al., 1987; Florsch and Hinderer, 2000; Ducarme et al., 2007) but has been better determined through its resonance effect in VLBI nutation data (Defraigne et al., 1994; Mathews et al., 2002; Koot et al., 2008; Rosat and Lambert, 2009; Rosat et al., 2017). An attempt has been done to retrieve FCN parameters even from very long-base hydrostatic tiltmeters (Riccardi et al., 2016) and strainmeters (Amoruso 

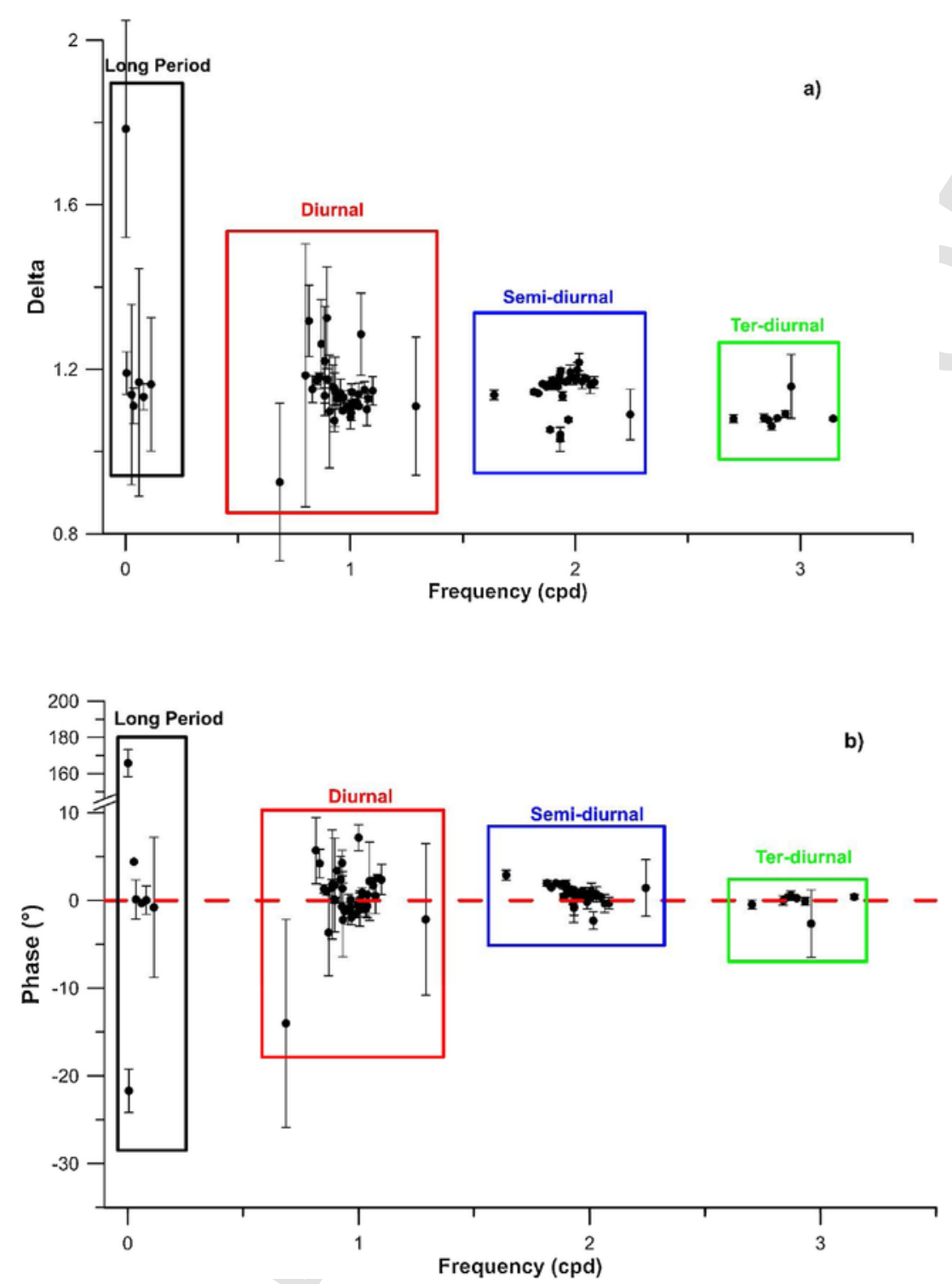

Fig. 5. Tidal gravimetric factors retrieved from tidal analysis; a) $\delta$ amplitude factors, b) phase $\left({ }^{\circ}\right.$ ).

et al., 2012). We refer to Rosat et al. (2009) for a summary of past FCN analyses.

From the tidal analysis results, we perform a Bayesian inversion based on the Metropolis-Hastings algorithm with a Markov-chain Monte Carlo method (described in Rosat et al., 2017) applied on the gravimetric complex $\delta$ factors corrected from the ocean tidal loading using a "mean" model (mean coming from the 9 ocean models previously quoted) and for various atmospheric corrections.

Since the ocean tides model do not provide amplitudes and phases for smaller diurnal waves, we have performed a spline interpolation of the tidal admittances of the main tides (Munk and Cartwright, 1966). In Fig. 7 one can see the diurnal gravimetric factors before and after ocean load reduction for the three atmospheric pressure reductions described below in the next section devoted to atmospheric loading.

It is well known from the tidal potential that the $\Psi 1$ wave, the closest to the resonance, is very small and even smaller at the latitude of Djougou, close to the equator. The error bars are larger than the values. Consequently, inverting for the FCN parameters from tidal resonance at Djougou is very challenging. Indeed, it turns out that we cannot put any constraint on the period and damping of the FCN mode from Djougou data. In Annex B we have enclosed an example of the
Bayesian inversion result applied on the $\delta$ factors using MERRA2 atmospheric correction. We obtain similar results using other sets of $\delta$ factors from various atmospheric corrections, with or without ocean tide loading reduction.

\section{Atmospheric loading}

As previously mentioned, the Djougou station is presently the only one of the IGETS network in operation in the equatorial band. It is hence of primary importance to study the air pressure effects on gravity in this region of the world. As can be seen in Fig. 8, the S1 and S2 waves of 1 and 2 cycle per solar day frequency respectively, have the largest amplitude in the equatorial band (e.g. Schindelegger and Ray, 2014) and we have an excellent opportunity to investigate their effects on gravity at Djougou station.

An example of the pressure changes in both time and frequency at Djougou is given by Fig. 9, where we also added the changes at the mid-latitude station Strasbourg.

In fact, S1 and S2 pressure waves are also strongly modulated in amplitude as shown by Fig. 10. The adjacent peaks around S1 (one cycle per solar day) and S2 (two cycles per solar day) are due to annual, 

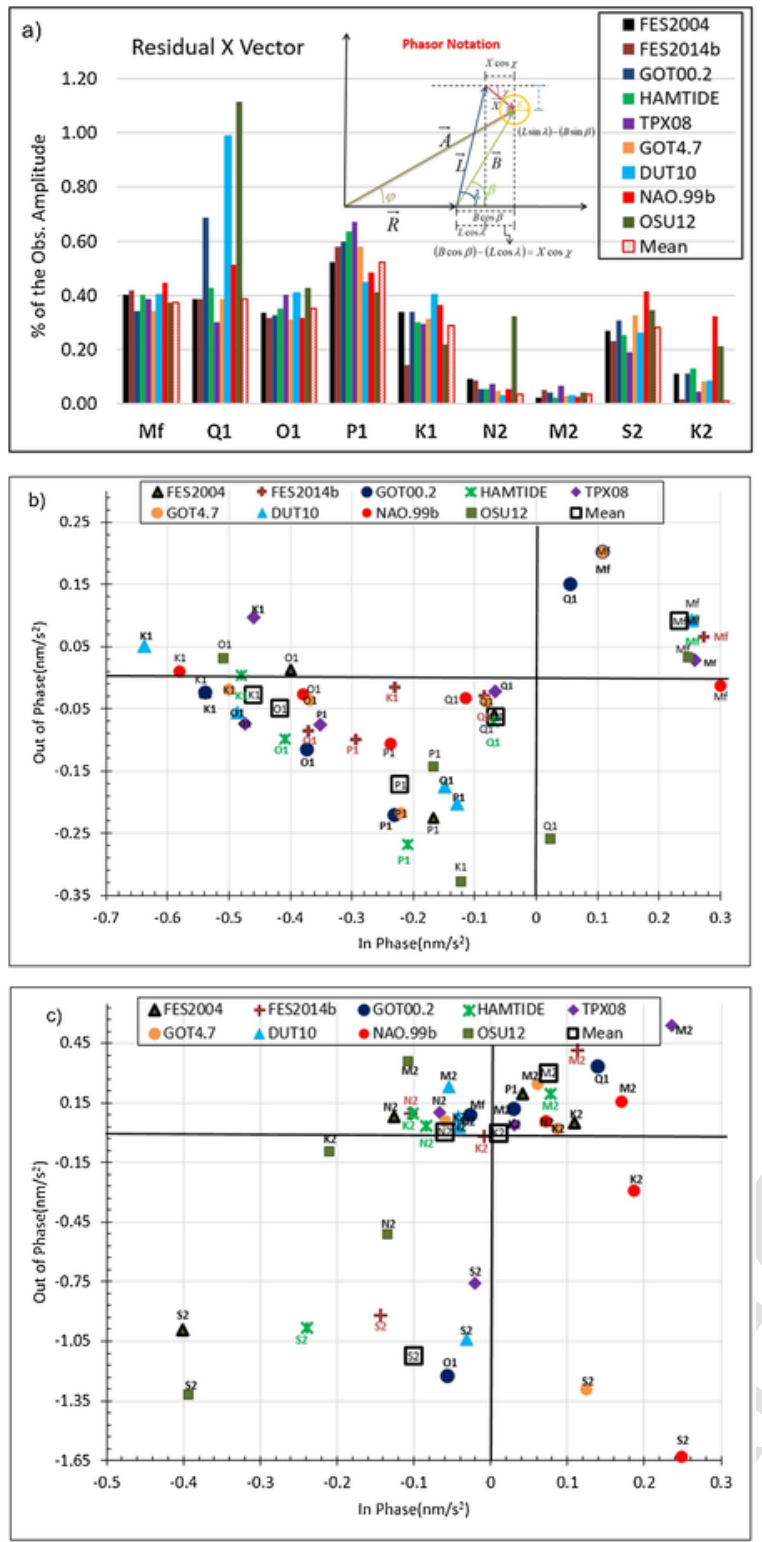

Fig. 6. Residual $\mathrm{X}$ vectors after ocean tide loading correction applied to the adjusted delta factors: a) amplitude of the residual vector (\% of adjusted amplitude). Real (in-phase) and Imaginary (out-of-phase) part of the residual vector for: b) diurnal, long period waves and c) semi-diurnal waves.

semi-annual and ter-annual modulation. This modulation was already pointed out in another study (Gegout et al., 1998) and is known to alter some specific tidal waves like P1 and K1 (by annual modulation) and PSI1 and PHI1 (by semi-annual modulation) in the diurnal band and T2 and R2 (by annual modulation) and 2T2 and K2 (by semi-annual modulation) in the semi-diurnal band. The existence of the modulated S1 pressure field of large scale may even lead to perturbations in the Earth's luni-solar nutations by pressure torque effects as stated by Gegout et al. (1998).

The air pressure also exhibits long period features among which the annual component Sa (one cycle per year) is the largest and other terms at Ssa (2 cycle per year) and Sta (3 cycle per year) (see Fig. 11 ).

We have superposed onto the spectrum of the observed air pressure $\mathrm{P}_{\text {obs }}$ the spectrum of the pressure $\mathrm{P}_{\text {model }}$ used in the atmospheric model ERA5 (Copernicus Climate Change Service (C3S) (2017). Since the time span of the model pressure is much longer (1979-2018) than the obser- vation time span (2010-2018) the spectral definition is much better for all the waves.

The question of the atmospheric pressure effects on gravity has been widely investigated in the literature (see Hinderer et al., 2015 for a review). Usually one introduces the concept of barometric admittance (in $\mathrm{nm} \mathrm{s}^{-2} / \mathrm{hPa}$ ) which can be either constant or time and frequency dependent (Crossley et al., 1995, 2002; Jensen et al. 1995). Observed gravity is then corrected for atmospheric effects using the computed barometric admittance. However the local pressure changes cannot account alone for the atmospheric loading as soon as the size of the coherent presure field exceeds a specific size (Merriam, 1992). To overcome this difficulty one has to compute the atmospheric loading effect at each station from the worlwide pressure field using surface pressure values on a grid (e.g. Boy et al., 2002) or, in the most sophisticated models, computing the 3D full effects where the changes of density with height are taken into account (Boy and Chao, 2005; Neumeyer et al., 2004; Gitlein et al., 2013; Klügel and Wziontek, 2009).

In this study we do not further discuss the transfer function between gravity and air pressure as a function of frequency. This was previously done for Djougou station in Hinderer et al. (2014b) for frequencies between $0.01 \mathrm{cpd}$ and $300 \mathrm{cpd}$ using a 2.5 year time span and similar results can be infered from this 8year analysis. In particular, we confirm the V shape (see Fig. 7 in Hinderer et al. (2014b) in the barometric admittance also seen elsewhere (Zürn and Widmer, 1995; Zürn and Wielandt, 2007; Zürn and Meurers, 2009).

We also added in Fig. 10 and Fig. 11 the spectra of the gravity changes (in $\mathrm{nm} \mathrm{s}^{-2}$ ) caused by the atmospheric load $\mathrm{P}_{\text {load }}$. At every spectral peak, there is an induced gravity load that will alter the tidal response. This gravity load is not a simple function of the local pressure (only the so-called local part is computed with a barometric admittance) but is more complicated because of the non-local part that involves the convolution of the pressure field worldwide with the atmospheric loading Green's function (see e.g. Boy et al., 2002).

The atmospheric gravity loading is computed using ECMWF (European Centre for Medium Range Weather Forecasts) operational and reanalysis (ERA interim) pressure data, assuming either an inverted barometer response of the oceans or a dynamic response using TUGO-m [Carrère and Lyard, 2003]. The use of the TUGO-m model has shown significant improvement in terms of reduction of the amplitude of the gravity residuals compared to the classical inverted barometer assumption [Boy and Lyard, 2008; Boy et al., 2009].

The gravity loading is composed of 3 terms:

- a "local" contribution (integration within $0.10^{\circ}$ or $0.25^{\circ}$ around the gravimeter) using nominal admittances of $-2.2105 \mathrm{~nm} . \mathrm{s}-2 / \mathrm{hPa}$ (radius of $0.10^{\circ}$ ) and $-3.0668 \mathrm{~nm} . \mathrm{s}-2 / \mathrm{hPa}$ (radius of $0.25^{\circ}$ )

- a "non-local" contribution

- the sum of the previous two, i.e. the complete loading model.

In the spectra shown by Fig. 10 and 11, the pressure loading in gravity $\mathrm{P}_{\text {load }}$ for the period 2010-2018 was computed from the ERA5 model using a $1 \mathrm{~h}$ sampling rate (derived by linear interpolation from the original $3 \mathrm{~h}$ time resolution) together with a $0.10^{\circ}$ local zone and inverted barometer ocean response.

The long-period part of the amplitude spectra of air pressure and gravity loading is shown on Fig. 11. The largest component is the annual term Sa followed by the semi-annual Ssa and ter-annual harmonics Sta.

Bearing in mind that, as shown by a number of authors (e.g. Riccardi et al., 2007; Hinderer et al., 2015), the single admittance concept is far from being a realistic account for the air pressure effect, we have tested two possible approaches, other than a single admittance coefficient, to correct the atmospheric effect on gravity: a) an a priori cor- 
(a)
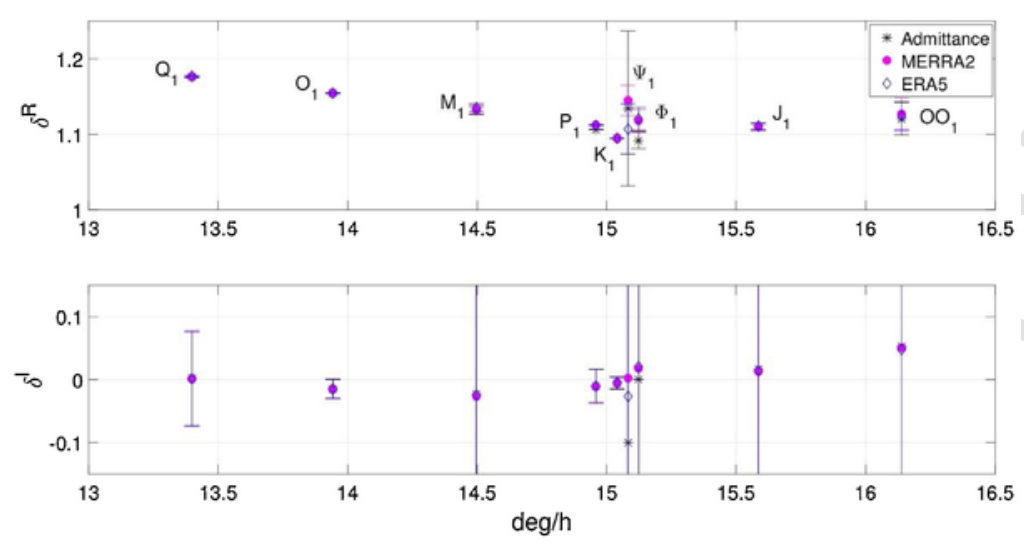

(b)
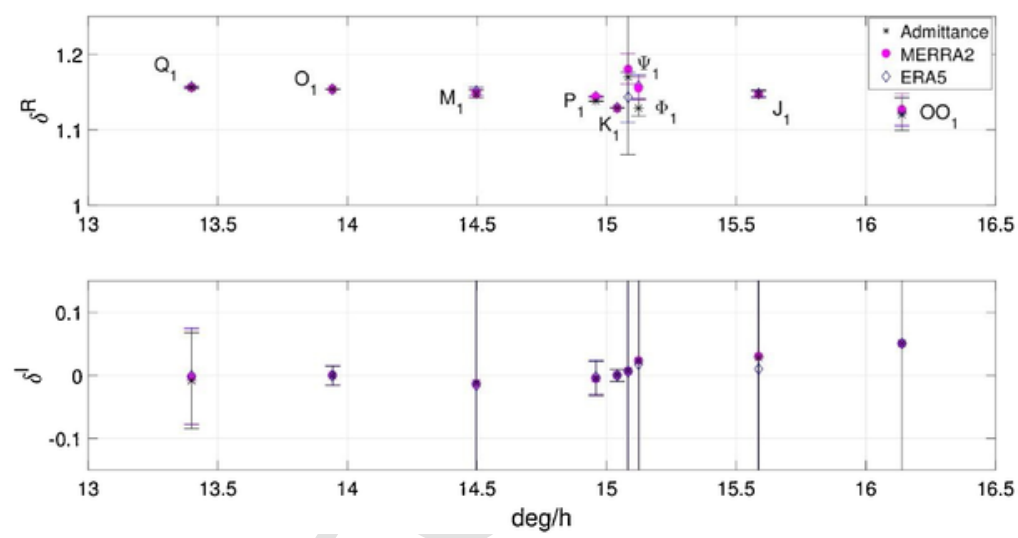

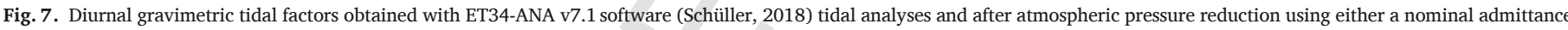

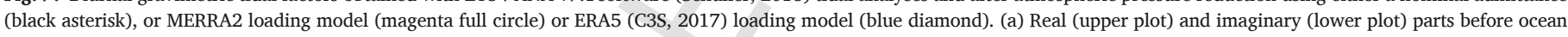
loading reduction; (b) real (upper plot) and imaginary (lower plot) parts after ocean loading reduction.

rection based on global load calculations (ERA5, MERRA2) available at (http://loading.u-strasbg.fr/GGP/); b) using a hybrid approach.

In a nutshell, the hybrid corrections are computed by retaining the modelled non-local component and replacing the local one with the observed air pressure multiplied by the nominal admittance coefficient coherently with model resolution. The hybrid method enables us to account both for very local atmospheric effects, as probed by the surface pressure observations, and larger scale contributions to gravity.

Some of the considered loading models also include atmospheric and induced oceanic loading and makes use of the ECMWF reanalysis (ERA interim) surface air pressure, assuming a barotropic ocean model forced by air pressure and winds (MOG2D, Carrère and Lyard, 2003).

Interpolating $3 \mathrm{~h}$ pressure data, $1 \mathrm{~h}$ resolution air pressure loading models are retrieved by splitting the contribution from the models into local and non-local components.

Performances of the different corrections are tested against the capability of an actual resolution of the tidal solar waves (Fig. 12). Notice that in Fig. 12 the gravity observations have been corrected for ocean tidal loading using the mean of the various ocean models available.

It is very clear that the classical admittance reduction based only on local pressure are clearly failing for Sa and S1. Global atmospheric models work better but the best results i.e. the smallest discrepancy between the reduced tidal amplitude factors and the solid Earth theoretical value (Dehant et al., 1999) are found using the hybrid models. A similar conclusion for S1 was obtained on other superconducting gravimeters of the international GGP network in a previous study (Boy et al., 2006).

\section{Conclusion}

Using an 8-year record (2010-2018) of the superconducting gravimeter OSG-060 at Djougou (Benin, West Africa) we investigated the solid Earth tides and ocean tidal loading. The tidal analysis was performed using ET34-ANA v7.1 software and led to the gravimetric amplitude and phase factors for all separable waves in various frequency bands ranging from the long period band to the quart-diurnal one.

Ocean tidal loading was computed from nine available global ocean tide models and allowed us to calculate the real and imaginary parts of the residual vector for the main eleven tidal constituents (Ssa, Mm, Mf, Q1, O1, P1, K1, N2, M2, S2, K2).

Because of the equatorial location of the Djougou station, atmospheric loading is dominated by the thermal waves S1 and S2. We have shown the annual and semi-annual amplitude modulations in the S1 and S2 pressure signals, as well as in the associated gravity loading using the global atmospheric model ERA5. In addition to S1 and S2, there are additional components in the long period band where the annual term SA dominates the semi-annual Ssa and ter-annual Sta terms.

We have shown how the amplitude gravimetric factors for the waves Sa, Ssa, S1 and S2 vary according to different air pressure cor- 

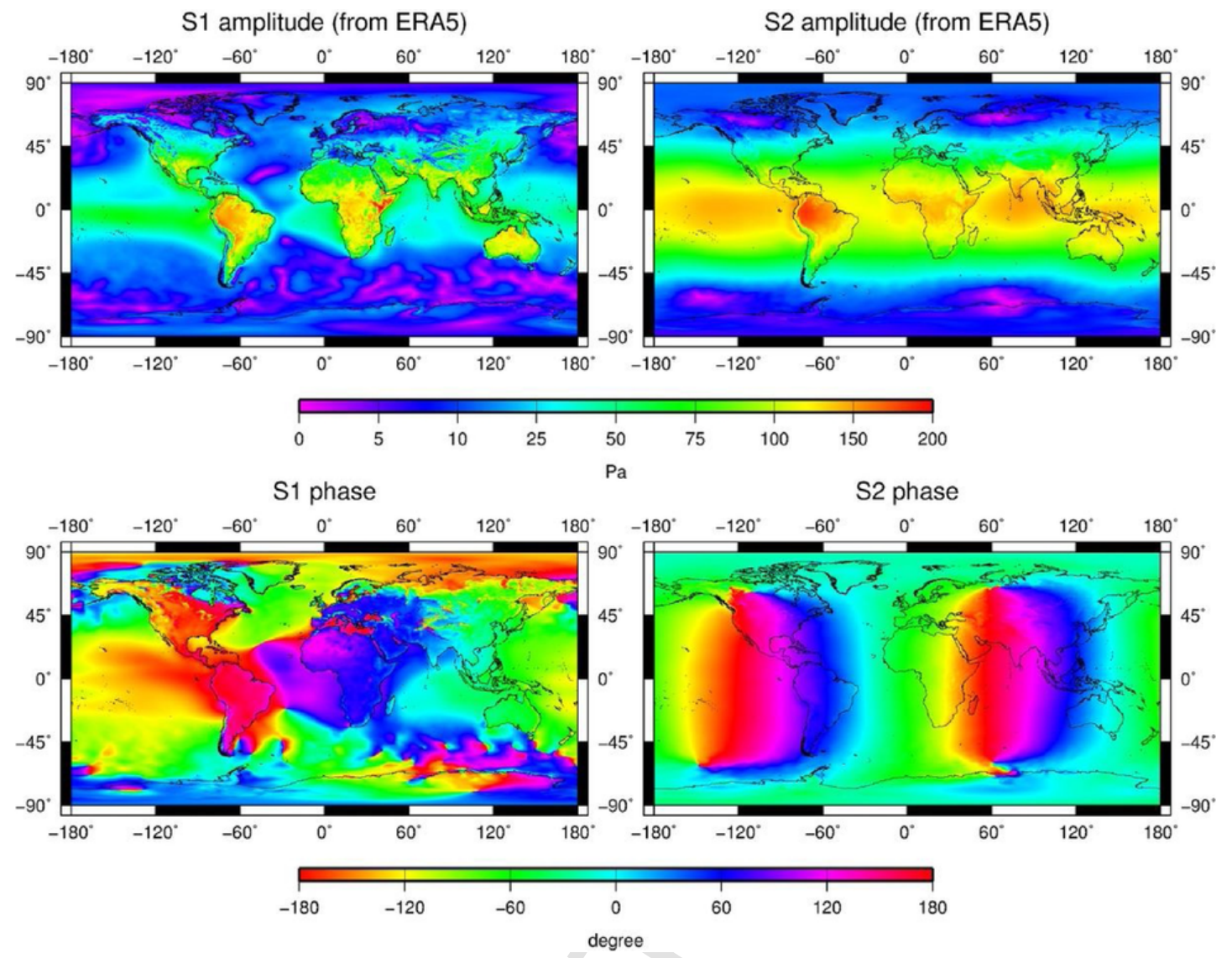

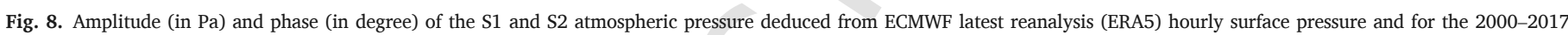
period.

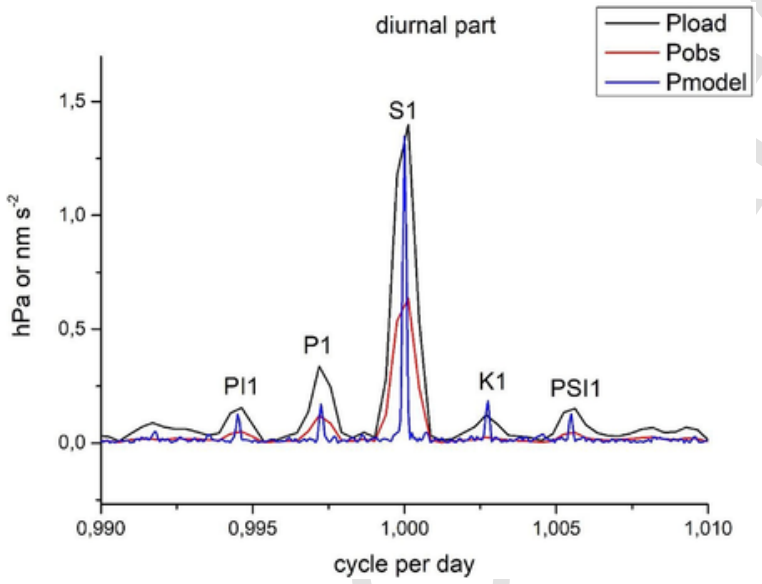

Fig. 9. Time and frequency changes of the atmospheric pressure at Djougou and Strasbourg (from Hinderer et al., 2014a).

rections. In particular, there is a large discrepancy between the classical single admittance pressure reduction and the hybrid model using global atmospheric models like ERA5 and MERRA2 everywhere except in the local zone where the model pressure is replaced by the observed pressure.

\section{Uncited references}

Baker and Bos (2003), Boy et al. (2003), Boy and Hinderer (2006), Copernicus Climate Change Service (C3S) (2017), Hinderer et al.

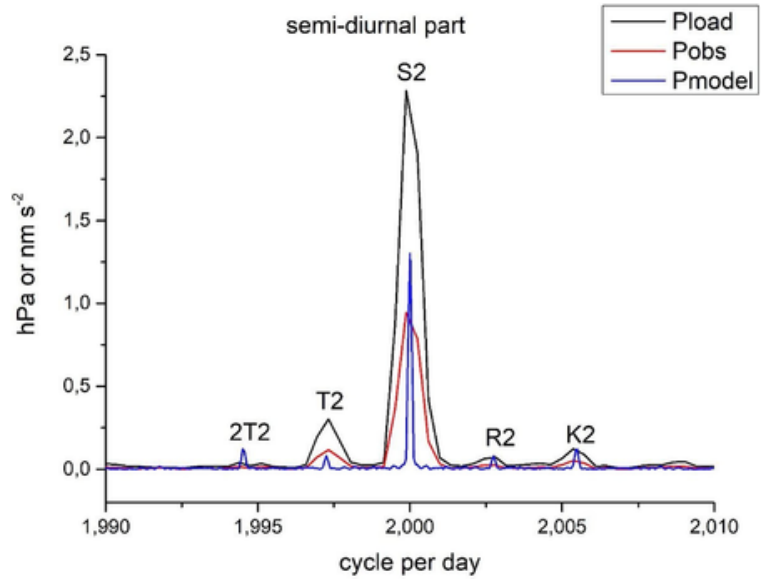

Fig. 10. Diurnal and semi-diurnal amplitude spectra of air pressure and induced gravity loading in Djougou. $\mathrm{P}_{\text {load }}$ is expressed in $\mathrm{nms}^{-2}, \mathrm{P}_{\text {obs }}$ and $\mathrm{P}_{\text {model }}$ are in $\mathrm{hPa}$. The spectra are normalized and use Hanning window filtering.

(2002), Ray and Egbert (2004), Ray and Ponte (2003), Rodell et al. (2004), Warburton and Goodkind (1977) and Wenzel (1996)

CRediT authorship contribution statement

Jacques Hinderer: Conceptualization, Methodology, Investigation, Supervision, Project administration. U. Riccardi: Methodology, Formal analysis, Investigation, Visualization. S. Rosat: Methodology, Formal analysis. J.-P. Boy: Methodology, Data curation. B. Hector: Investigation. M. Calvo: Data curation. F. Little: Resources. J.-D. Bernard: Resources. 


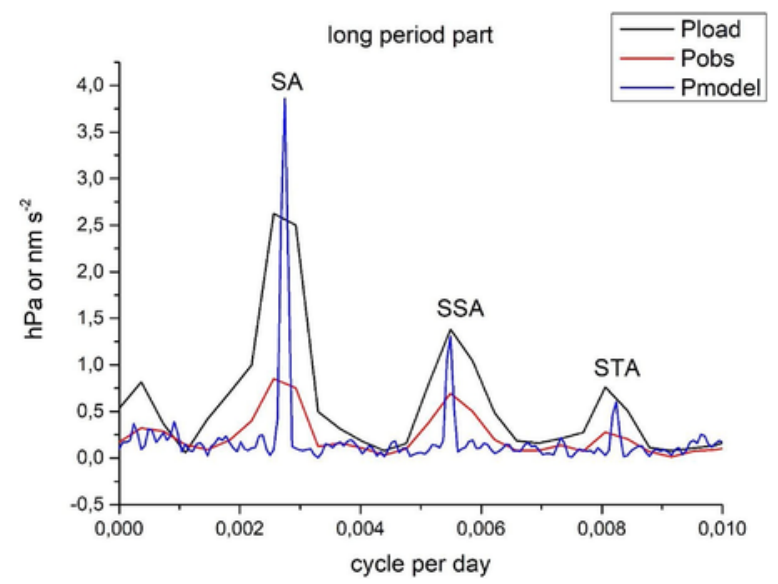

Fig. 11. Long-period amplitude spectra of air pressure and induced gravity loading in Djougou. $\mathrm{P}_{\text {load }}$ is expressed in $\mathrm{nms}^{-2}, \mathrm{P}_{\text {obs }}$ and $\mathrm{P}_{\text {model }}$ are in $\mathrm{hPa}$. The spectra are normalized and use Hanning window filtering.

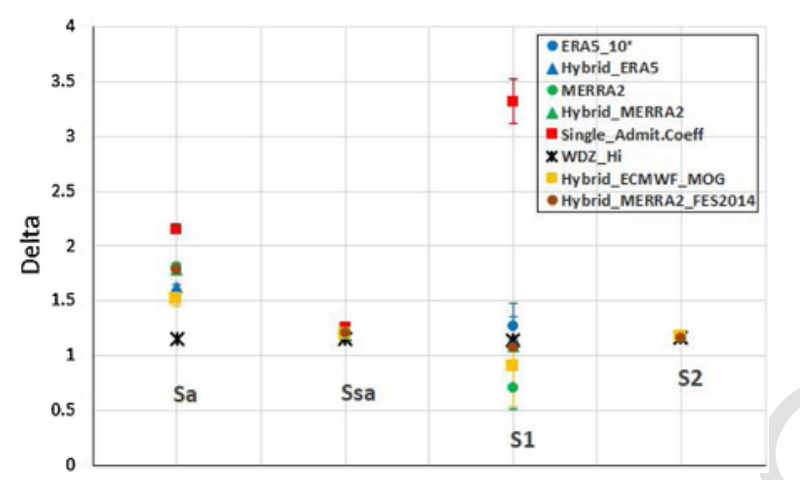

Fig. 12. Amplitude gravimetric factors (Delta) according to different air pressure corrections. The red square uses the classical single admittance coefficient. Blue and green circles use the global atmospheric models ERA5 and MERRA2 respectively. Blue and green triangles replace in ERA5 and MERRA2 the model pressure in the local zone by the observed pressure. The black cross is the theoretical value predicted for a slightly inelastic Earth's model (Dehant and Zschau, 1989. Dehant et al., 1999).

\section{Acknowledgments}

We acknowledge the financial support of INSU-CNRS for operating SG 060 in Djougou as part of the French Observatory Service (SNO Gravimétrie).

\section{Annex A}

Adjusted parameters ( $\delta$ and $\mathrm{k}$ ) of a tidal analysis carried out with ET34-ANA-v71 software (Schüller, 2018) on the data set spanning 22 July 2010 - 31 March 2018 (Recorded days in total: 2809). Instrumental drift, hydrological and atmospheric effects are reduced before applying the analysis. Hydrological effects are modelled by MERRA2, while the atmospheric effects are accounted by following the hybrid MERRA2 approach (see the main text for details).

\begin{tabular}{|c|c|c|c|c|c|c|}
\hline Wave & $\begin{array}{l}\text { f_Min } \\
\text { (cpd) }\end{array}$ & $\begin{array}{l}\text { f_Max } \\
\text { (cpd) }\end{array}$ & $\begin{array}{l}\mathrm{A}_{\mathrm{th}}(\mathrm{nm} / \\
\left.\mathrm{s}^{2}\right)\end{array}$ & $\delta$ & $\delta$ error & $\mathrm{k}\left({ }^{\circ}\right)$ \\
\hline Sa & 0.000002 & 0.004067 & 24.75239 & 1.78 & 0.26 & 165.8 \\
\hline Ssa & 0.004068 & 0.006600 & 27.46238 & 1.191 & 0.052 & $-21.7 \mathrm{C}$ \\
\hline Sta & 0.006601 & 0.019600 & 1.60491 & 3.48 & 0.89 & 7.1 \\
\hline Msm & 0.019601 & 0.035200 & 5.96317 & 1.14 & 0.22 & 4.4 \\
\hline $\mathrm{Mm}$ & 0.035201 & 0.036700 & 31.18492 & 1.111 & 0.043 & 0.12 \\
\hline NO & 0.036701 & 0.051333 & 1.66864 & 1.50 & 0.95 & 11.0 \\
\hline Msf & 0.051334 & 0.069242 & 5.17328 & 1.17 & 0.28 & -0.3 \\
\hline $2 \mathrm{Mm}$ & 0.069243 & 0.073000 & 2.55586 & 1.11 & 0.54 & 3.2 \\
\hline Mf & 0.073001 & 0.089333 & 59.02746 & 1.133 & 0.032 & 0.03 \\
\hline SN & 0.089334 & 0.104367 & 0.81995 & 0.81 & 1.80 & -12.9 \\
\hline Mstm & 0.104368 & 0.10558 & 2.14615 & 1.11 & 0.88 & -6.1 \\
\hline Mtm & 0.105581 & 0.122801 & 11.30189 & 1.16 & 0.16 & -0.8 \\
\hline MSqm & 0.122802 & 0.14449 & 1.80510 & 1.230 & 1.002 & 1.3 \\
\hline Mqm & 0.144491 & 0.16000 & 1.49519 & 1.08 & 1.23 & 0.5 \\
\hline SKNMO & 0.160001 & 0.40000 & 0.43615 & 1. 18 & 3.73 & 12.7 \\
\hline SGM2Q1 & 0.58 & 0.791600 & 0.12655 & 0.93 & 0.19 & -14.0 \\
\hline 2SGM1 & 0.791601 & 0.810000 & 0.07851 & 1.185 & 0.320 & 15.6 \\
\hline 3Q1 & 0.810001 & 0.821300 & 0.29485 & 1.318 & 0.087 & 5.7 \\
\hline SGMQ1 & 0.821301 & 0.842147 & 0.76384 & 1.152 & 0.033 & 4.23 \\
\hline 2Q1 & 0.842148 & 0.860500 & 2.62170 & 1.173 & 0.010 & 1.32 \\
\hline SGM1 & 0.860501 & 0.863000 & 3.16152 & 1.183 & 0.008 & 1.02 \\
\hline SGMb1 & 0.863001 & 0.878675 & 0.21341 & 1.26 & 0.11 & -3.7 \\
\hline Qa1 & 0.878676 & 0.892935 & 0.16654 & 1.22 & 0.13 & 1.8 \\
\hline
\end{tabular}
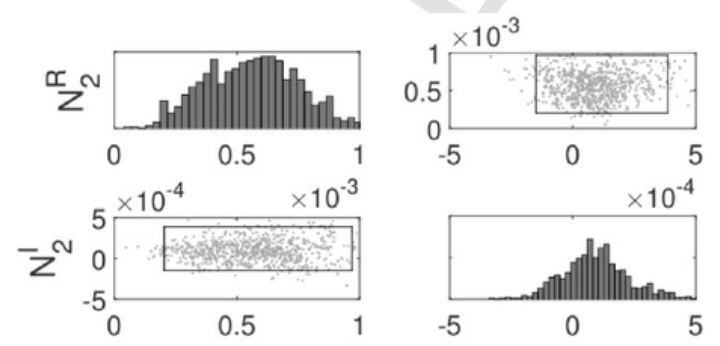

$\times 10^{-3}$
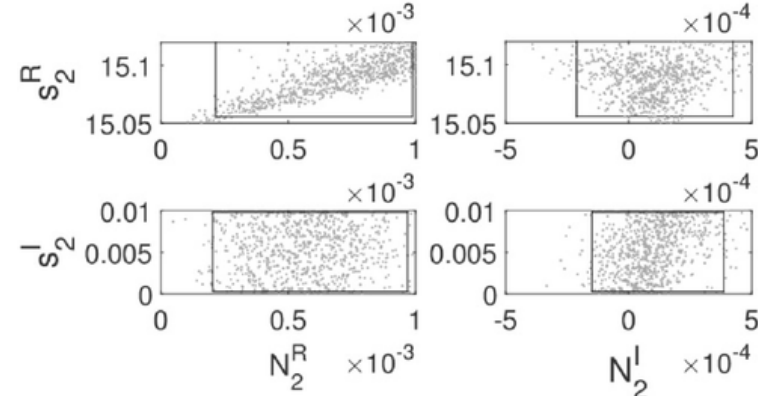
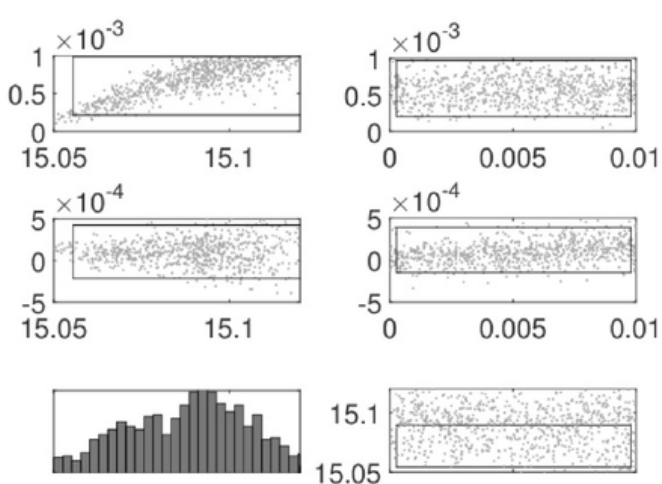

15.05

15.1
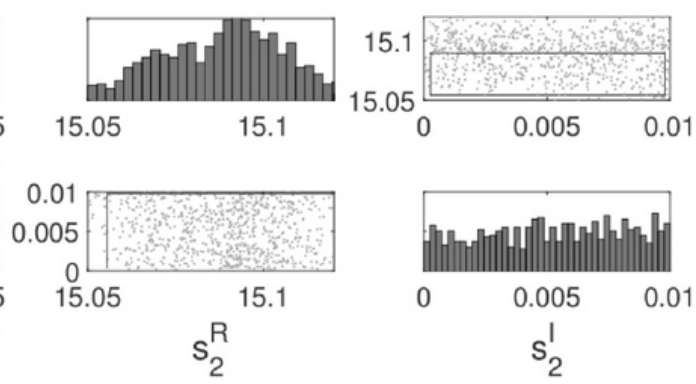

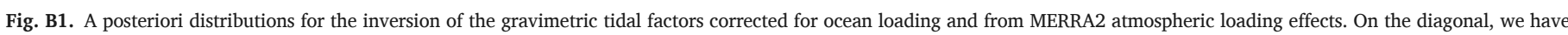

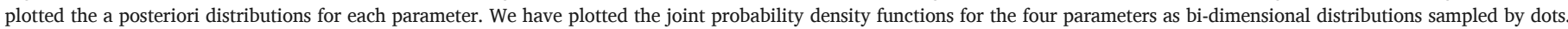

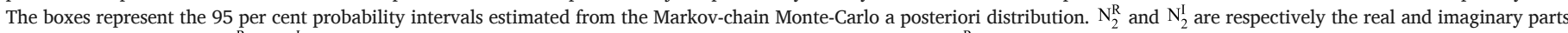
of the resonance strength. $\mathrm{s}_{2}^{\mathrm{R}}$ and $\mathrm{s}_{2}^{\mathrm{I}}$ are respectively the real and imaginary parts of the complex FCN frequency. $\mathrm{s}_{2}^{\mathrm{R}}$ is given in deg/h. 


\begin{tabular}{|c|c|c|c|c|c|c|}
\hline Q1 & 0.892936 & 0.895000 & 19.81164 & 1.176 & 0.001 & 0.09 \\
\hline Qb1 & 0.895001 & 0.896800 & 0.18482 & 1.32 & 0.12 & 1.75 \\
\hline RO1 & 0.896801 & 0.899000 & 3.76048 & 1.174 & 0.007 & 0.03 \\
\hline ROb1 & 0.899001 & 0.91500 & 0.17363 & 1.10 & 0.14 & 3.4 \\
\hline Oa1 & 0.915001 & 0.928315 & 0.35555 & 1.157 & 0.053 & 2.4 \\
\hline O1 & 0.928316 & 0.92996 & 103.47391 & 1.15458 & 0.00027 & -0.7 \\
\hline $2 \mathrm{NO} 1$ & 0.929961 & 0.93100 & 0.66663 & 1.152 & 0.039 & 1.37 \\
\hline Ob1 & 0.931001 & 0.9332 & 0.31311 & 1.145 & 0.084 & -2.2 \\
\hline TAU1 & 0.933201 & 0.947991 & 1.34876 & 1.128 & 0.014 & -1.2 \\
\hline NTAU1 & 0.947992 & 0.96446 & 0.76304 & 1.142 & 0.034 & -1.0 \\
\hline LK1 & 0.964461 & 0.965933 & 2.92535 & 1.129 & 0.009 & -0.7 \\
\hline NO1 & 0.965934 & 0.966853 & 8.13371 & 1.133 & 0.003 & -1.3 \\
\hline CHI1 & 0.966854 & 0.971667 & 1.55640 & 1.131 & 0.016 & -1.9 \\
\hline PI1 & 0.971668 & 0.996933 & 2.81317 & 1.109 & 0.008 & -1.5 \\
\hline P1 & 0.996934 & 0.998631 & 48.13841 & 1.11271 & 0.00047 & -0.5 \\
\hline S1 & 0.998632 & 1.002333 & 1.13763 & 1.083 & 0.028 & 7.16 \\
\hline K1 & 1.002334 & 1.004200 & 145.46657 & 1.09452 & 0.00017 & -0.2 \\
\hline PSI1 & 1.004201 & 1.006845 & 1.13816 & 1.145 & 0.020 & 0.09 \\
\hline PHI1 & 1.006846 & 1.023622 & 2.07114 & 1.118 & 0.011 & 0.90 \\
\hline TET1 & 1.023623 & 1.035379 & 1.55595 & 1.119 & 0.016 & -1.0 \\
\hline $\mathrm{J} 1$ & 1.03538 & 1.039400 & 8.13659 & 1.110 & 0.004 & 0.68 \\
\hline KLK1 & 1.039401 & 1.055000 & 0.12579 & 1.76 & 0.46 & -27 \\
\hline SO1 & 1.055001 & 1.070867 & 1.34940 & 1.150 & 0.020 & 1.72 \\
\hline $2 \mathrm{~J} 1$ & 1.070868 & 1.075633 & 0.66696 & 1.103 & 0.039 & 0.53 \\
\hline OO1 & 1.075634 & 1.086000 & 4.45009 & 1.128 & 0.007 & 2.60 \\
\hline NU1 & 1.086001 & 1.112600 & 0.85219 & 1.148 & 0.035 & 2.39 \\
\hline 2(KM)P1 & 1.112601 & 1.470243 & 0.13608 & 1.11 & 0.17 & -2.1 \\
\hline 2EPS2 & 1.470244 & 1.808000 & 0.89043 & 1.138 & 0.012 & 2.89 \\
\hline $3 N 2$ & 1.808001 & 1.824458 & 2.07795 & 1.146 & 0.006 & 1.98 \\
\hline EPS2 & 1.824459 & 1.845944 & 5.38607 & 1.142 & 0.002 & 1.49 \\
\hline $2 \mathrm{~N} 2$ & 1.845945 & 1.863026 & 18.46935 & 1.165 & 0.001 & 1.99 \\
\hline MUE2 & 1.863027 & 1.880264 & 22.29099 & 1.158 & 0.001 & 1.85 \\
\hline $\mathrm{Na} 2$ & 1.880265 & 1.89568 & 1.17291 & 1.161 & 0.010 & 1.77 \\
\hline N2 & 1.895681 & 1.897351 & 139.56986 & 1.17222 & 0.00010 & 1.45 \\
\hline $\mathrm{Nb} 2$ & 1.897352 & 1.899500 & 1.30213 & 1.171 & 0.009 & 1.89 \\
\hline NUE2 & 1.899501 & 1.902300 & 26.51222 & 1.17362 & 0.00049 & 1.37 \\
\hline NUEb2 & 1.902301 & 1.915114 & 1.22281 & 1.161 & 0.011 & 0.91 \\
\hline GAM2 & 1.915115 & 1.928402 & 2.18840 & 1.158 & 0.006 & 1.26 \\
\hline ALF2 & 1.928403 & 1.930667 & 2.50419 & 1.182 & 0.005 & -0.1 \\
\hline M2 & 1.930668 & 1.93379 & 728.95288 & 1.17265 & 0.00002 & 1.19 \\
\hline BET2 & 1.933791 & 1.936152 & 2.20607 & 1.197 & 0.006 & 0.71 \\
\hline DEL2 & 1.936153 & 1.950419 & 0.85456 & 1.135 & 0.010 & 0.58 \\
\hline LAM2 & 1.95042 & 1.964767 & 5.37527 & 1.170 & 0.002 & 0.49 \\
\hline L2 & 1.964768 & 1.9686 & 20.60601 & 1.172 & 0.001 & 0.88 \\
\hline KNO2 & 1.968601 & 1.9703 & 5.15017 & 1.174 & 0.003 & 1.04 \\
\hline JTAU2 & 1.970301 & 1.984282 & 0.98519 & 1.192 & 0.018 & 0.67 \\
\hline $2 \mathrm{~T} 2$ & 1.984283 & 1.9955 & 0.80407 & 1.180 & 0.017 & -0.1 \\
\hline $\mathrm{T} 2$ & 1.995501 & 1.998996 & 19.81731 & 1.177 & 0.001 & 0.62 \\
\hline S2 & 1.998997 & 2.001678 & 339.11676 & 1.17489 & 0.00004 & 0.61 \\
\hline R2 & 2.001679 & 2.00438 & 2.82993 & 1.180 & 0.004 & 0.29 \\
\hline K2 & 2.004381 & 2.0058 & 92.13440 & 1.17497 & 0.00017 & 0.76 \\
\hline $\mathrm{Kb} 2$ & 2.005801 & 2.010635 & 0.72097 & 1.199 & 0.019 & 1.11 \\
\hline KPHI2 & 2.010636 & 2.022488 & 0.62762 & 1.217 & 0.021 & -2.2 \\
\hline ZETA2 & 2.022489 & 2.0384 & 0.98534 & 1.170 & 0.017 & 0.72 \\
\hline ETA2 & 2.038401 & 2.056 & 5.15376 & 1.178 & 0.003 & 0.44 \\
\hline $2 \mathrm{~S} 2$ & 2.056001 & 2.0758 & 0.85475 & 1.162 & 0.020 & -0.3 \\
\hline $2 \mathrm{~K} 2$ & 2.075801 & 2.092667 & 1.34828 & 1.168 & 0.014 & -0.3 \\
\hline 2KN2 & 2.092668 & 2.396 & 0.25823 & 1.090 & 0.062 & 1.44 \\
\hline M2N3 & 2.5800 & 2.8266 & 0.67006 & 1.080 & 0.010 & -0.4 \\
\hline MMUE3 & 2.826601 & 2.85000 & 0.67357 & 1.082 & 0.010 & 0.01 \\
\hline MN3 & 2.850001 & 2.86430 & 3.86508 & 1.077 & 0.002 & 0.37 \\
\hline MNUE3 & 2.864301 & 2.88000 & 0.72357 & 1.062 & 0.009 & 0.55 \\
\hline M3 & 2.880001 & 2.915496 & 14.10341 & 1.08137 & 0.00049 & 0.27 \\
\hline ML3 & 2.915497 & 2.953157 & 0.79874 & 1.091 & 0.008 & -0.0 \\
\hline MK3 & 2.953158 & 3.340000 & 1.83703 & 1.080 & 0.005 & 0.41 \\
\hline
\end{tabular}

\section{Annex B. Bayesian inversion results for the FCN resonance parameters}

We employ the same inversion algorithm as in Rosat et al. (2017) with the resonance equation defined as
$\delta=\delta_{0}+\frac{N_{2}}{\sigma-s_{2}}$

where $N_{2}$ is the resonance strength, $\delta_{0}$ is the tidal response far from the FCN resonance taken here as the mean value of the observed gravimetric factors for Q1 and 0O1. $s_{2}$ is the complex frequency of the FCN and the quality factor is obtained from the real and imaginary parts of the frequency by $Q=\frac{s_{2}^{R}}{2 s_{2}^{I}}$. $\sigma$ is the frequency of the forcing tidal constituent. We assume uniform prior distributions for the parameters that we inverse. A priori information, particularly in ill-posed inverse problem like the current one, is of critical importance because it is conditioning the a posteriori solution. In other words, a completely unresolved parameter has a posteriori marginal density function that follows the a priori one. So the more the a posteriori density function differs from the a priori one, the more the parameter has been resolved.

We can see in Fig. B1 that the strength of the resonance is well constrained since the a posteriori distributions are Gaussian. However, the complex frequency of the FCN spans the full range of the a priori distribution without converging to a preferred value: the complex frequency is not resolved from the data. The dot distribution between $s_{2}^{R}$ and $N_{2}^{R}$ shows a tilted shape that is characteristic of a correlation between both parameters (e.g. Florsch and Hinderer, 2000).

\section{References}

Amoruso, A., Botta, V., Crescentini, L., 2012. Free core resonance parameters from strain data: sensitivity analysis and results from the Gran Sasso (Italy) extensometers. Geophys. J. Int. 189, 923-936.

Boy, J.-P., Chao, B.F., 2005. Precise evaluation of atmospheric loading effects on Earth's time-variable gravity field. J. Geophys. Res. 110, B08412https://doi.org/10.1029/ 2002JB002333.

Boy, J.-P., Gegout, P., Hinderer, J., 2002. Reduction of surface gravity data from global atmospheric pressure loading. Geophys. J. Int. 149, 534-545.

Boy, J.-P., Hinderer, J., 2006. Study of the seasonal gravity signal in superconducting gravimeter data. J. Geodyn. 41, 227-233.

Boy, J.-P., Lyard, F., 2008. High-frequency non-tidal ocean loading effects on surface gravity measurements. Geophys. J. Int. 175, 35-45.

Boy, J.-P., Ray, R., Hinderer, J., 2006. Diurnal atmospheric tide and induced gravity variations. J. Geodyn. 41, 253-258.

Boy, J.-P., Longuevergne, L., Boudin, F., Jacob, T., Lyard, F., Llubes, M., Florsch, N., Esnoult, M.-F., 2009. Modelling atmospheric and induced non-tidal oceanic loading contributions to surface gravity and tilt measurements. J. Geodyn. 48, 182-188. https:// doi.org/10.1016/j.jog.2009.09.022.

Carrère, L., Lyard, F., 2003. Modeling the barotropic response of the global ocean to atmospheric wind and pressure forcing - comparisons with observations. Geophys. Res. Lett. 30, https://doi.org/10.1029/2002GL016473.

Carrère, L., Lyard, F., Cancet, M., 2015. FES2014, A New Tidal Model on the Global Ocean With Enhanced Accuracy in Shallow Seas and in the Arctic Region, EGU General Assembly 2015. 12-17, April Vienna (Austria).

Cheng, Y., Andersen, O.B., 2010. Improvement in global ocean tide model in shallow water regions. In: Proceedings of the OSTST Meeting. Lisbon. pp. 18-22, October.

Copernicus Climate Change Service (C3S), 2017. ERA5: Fifth Generation of ECMWF Atmospheric Reanalyses of the Global Climate. Copernicus Climate Change Service Climate Data Store (CDS), date of accessIn: https://cds.climate.copernicus.eu/cdsapp\#!/ home.

Crossley, D.J., Jensen, O.G., Hinderer, J., 1995. Effective barometric admittance and gravity residuals. Phys Earth Planet Int 90, 221-241.

Crossley, D., Hinderer, J., Rosat, S., 2002. Using the atmosphere-gravity correlation to derive a time-dependent admittance. Bull Inform Mar Terr 136, 10809-10820.

Crossley, D., Calvo, M., Rosat, S., Hinderer, J., 2018. More Thoughts on AG-SG Comparisons and SG Scale Factor Determinations. Pure Appl. Geophysics, Springer International Publishing AGhttps://doi.org/10.1007/s00024-018-1834-9.

Defraigne, P., Dehant, V., Hinderer, J., 1994. Stacking gravity tide measurements and nutation observations in order to determine the complex eigenfrequency of the nearly diurnal free wobble. J. Geophys. Res. Solid Earth 99 (B5), 9203-9213.

Dehant, V., Zschau, J., 1989. The effect of mantle inelasticity on tidal gravity: a comparison between the spherical and the elliptical Earth model.". Geophys. J. 97, 549-555.

Dehant, V., Defraigne, P., Wahr, J.M., 1999. Tides for a convective earth. J. Geophys. Res. 104 (B1), 1035-1058

Ducarme, B., Sun, H.-P., Xu, J.-Q., 2007. Determination of the free core nutation period from tidal gravity observations of the GGP superconducting gravimeter network. J. Geod. 81, 179-187. 
Egbert, G.D., Erofeeva, L., 2002. Efficient inverse modeling of barotropic ocean tides. J. Atmos. Oceanic Technol. 19 (2), 183-204.

Florsch, N., Hinderer, J., 2000. Bayesian estimation of the free core nutation parameters from the analysis of precise tidal gravity data. Phys. Earth Planet Inter. 117, 21-35.

Fok, H.S., 2012. Ocean Tides Modeling Using Satellite Altimetry. Report No. 501, Geodetic Science Report, Ohio State University.

Gegout, P., Hinderer, J., Legros, H., Greff, M., Dehant, V., 1998. Influence of atmospheric pressure on the Free Core Nutation, precession and some forced nutational motions of the Earth. Phys. Earth Planet. Int. 106, 337-351.

Gitlein, O., Timmen, L., Müller, J., 2013. Modeling of atmospheric gravity effects for high-precision observations. Int. J. Geosci. 4 (4), 2013.

Habel, B., Meurers, B., 2014. A new tidal analysis of superconducting gravity observations in Western and Central Europe. Contrib Geophys. Geod. 44 (1), 1-24.

Hartmann, T., Wenzel, H.G., 1995. The HW95 tidal potential catalogue. Geophys. Res. Lett. 22 (24), 3553-3556.

Hector, B., Hinderer, J., Séguis, L., Boy, J.-P., Calvo, M., Descloitres, M., Rosat, S., Galle, S., Riccardi, U., 2014. Hydro-gravimetry in West-Africa: first results from the Djougou (Benin) superconducting gravimeter. J. Geodyn. 80, 34-49. https://doi.org/10.1016/ j.jog.2014.04.003.

Hinderer, J., Florsch, N., Mäkinen, J., Legros, H., Faller, J.E., 1991. On the calibration of a superconducting gravimeter using absolute gravity measurements. Geophys. J. Int. 106, 491-497.

Hinderer, J., Rosat, S., Crossley, D., Amalvict, M., Boy, J.P., Gégout, P., 2002. Influence of different processing methods on the retrieval of gravity signals from GGP data. Bull Inform Mar Terr 135, 10653-10668.

Hinderer, J., Pfeffer, J., Boucher, M., Nahmani, S., De Linage, C., Boy, J.-P., Genthon, P., Seguis, L., Favreau, G., Bock, O., et al., 2012. Land water storage changes from ground and space geodesy: first results from the GHYRAF (Gravity and Hydrology in Africa) experiment. Pure Appl Geophys 169 (8), 1391-1410. https://doi.org/10. 1007/s00024-011-0417-9.

Hinderer, J., Crossley, D., Warburton, R., 2015. Superconducting gravimetry, in treatise on geophysics. In: In: Herring, T., Schubert, G. (Eds.), Geodesy, vol. 3, Elsevier Science Technology, United Kingdom, pp. 65-122.

Hinderer, J., Rosat, S., Calvo, M., Boy, J.-P., Hector, B., Riccardi, U., Séguis, L., 2014. Preliminary results from the superconducting gravimeter SG-060 installed in West Africa (Djougou, Benin). In: Rizos, C., Willis, P. (Eds.), Earth on the Edge: Science for a Sustainable Planet, International Association of Geodesy Symposia, Springer, Berlin Heidelberg, pp. 413-419.

Hinderer, J., Hector, B., Boy, J.-P., Riccardi, U., Rosat, S., Calvo, M., Littel, F., 2014. A search for atmospheric effects on gravity at different time and space scales. J. Geodyn. 80, 50-57.

Imanishi, Y., Higashi, T., Fukuda, Y., 2002. Calibration of the superconducting gravimeter T011 by parallel observation with the absolute gravimeterFG5\#210 - a Bayesian approach. Geophys. J. Int. 151, 867-878.

Klügel, T., Wziontek, H., 2009. Correcting gravimeters and tiltmeters for atmospheric mass attraction using operational weather models. J. Geodyn. 48, 204-210.

Koot, L., Rivoldini, A., de Viron, O., Dehant, V., 2008. Estimation of Earth interior parameters from a Bayesian inversion of very long baseline interferometry nutation time series. J. Geophys. Res. 113, B08414https://doi.org/10.1029/2007JB005409.

Lyard, F.H., Lefevre, F., Letellier, T., Francis, O., 2006. Modelling the global ocean tides: modern insights from FES2004. Ocean Dyn. 56, 394-415. https://doi.org/10.1007/ s10236-006-0086-x.

Matsumoto, K., Takanezawa, T., Ooe, M., 2000. Ocean tide models developed by assimilating TOPEX/POSEIDON altimeter data into hydrodynamical model: a global model and a regional model around Japan. J. Oceanogr. 56, 567-581.

Mathews, P.M., Herring, T.A., Buffet, B.A., 2002. Modeling of nutation and precession: new nutation series for nonrigid Earth and insights into the Earth's interior. J. Geophys. Res. 107 (B4), 2068. https://doi.org/10.1029/2001JB000390.
Merriam, J., 1992. Atmospheric pressure and gravity. Geophys. J. Int. 109, 488-500.

Munk, W.H., Cartwright, D.E., 1966. Tidal spectroscopy and prediction. Philos. Trans. Biol. Sci. 259 (1105), 533-581.

Neuberg, J., Hinderer, J., Zürn, W., 1987. Stacking gravity tide observations in Central Europe for the retrieval of the complex eigenfrequency of the nearly diurnal free wobble. Geophys. J. Roy. Astron. Soc. 91, 853-868.

Neumeyer, J., Hagedoorn, J., Leitloff, J., Schmidt, T., 2004. Gravity reduction with three-dimensional atmospheric pressure data for precise ground gravity measurements. J. Geodyn. 38 (3-5), 437-450. https://doi.org/10.1016/j.jog.2004.07.006.

Ray, R.D., 1999. A Global Ocean Tide Model From TOPEX/POSEIDON Altimetry: GOT99.2. NASA Technical Memorandum, 209478.

Reichle, R.H., Draper, C., Liu, Q., Girotto, M., Mahanama, S., Koster, R., De Lannoy, G., 2017. Assessment of MERRA-2 land surface hydrology estimates. J. Climate https:// doi.org/10.1175/JCLI-D-16-0720.1.

Riccardi, U., Hinderer, J., Boy, J., 2007. On the efficiency of barometric arrays to improve the corrections of atmospheric effects on gravity data. Phys. Earth Planet. Inter. 161 (3-4), 224-242. https://doi.org/10.1016/j.pepi.2007.02.007.

Riccardi, U., Rosat, S., Hinderer, J., 2012. On the accuracy of the calibration of superconducting gravimeters using absolute and spring sensors: a critical comparison. Pure Appl. Geophys. 169 (8), 1343-1356. https://doi.org/10.1007/s00024-011-0398-8.

Riccardi, U., Boy, J.P., Hinderer, J., Rosat, S., Boudin, F., 2016. Free core nutation parameters from hydrostatic Long-Base tiltmeter records in sainte Croix aux mines (France) In: In: Freymueller, J.T., Sánchez, L. (Eds.), INternational Symposium on Earth and Environmental Sciences for Future Generations. International Association of Geodesy Symposia, vol. 147, pp. 171-179. https://doi.org/10.1007/1345_2016_260.

Rosat, S., Lambert, S.B., 2009. Free core nutation resonance parameters from VLBI and superconducting gravimeter data. Astron. Astrophys. 503, 287-291.

Rosat, S., Florsch, N., Hinderer, J., Llubes, M., 2009. Estimation of the free core nutation parameters from SG data: sensitivity study and comparative analysis using linearized least-squares and bayesian methods. J. Geodyn. 48, 331-339.

Rosat, S., Lambert, S.B., Gattano, C., Calvo, M., 2017. Earth's core and inner core resonances from analysis of VLBI nutation and superconducting gravimeter data. Geophys. J. Int. 208, 211-220.

Schindelegger, M., Ray, R., 2014. Surface pressure tide climatologies deduced from quality-controlled network of barometric observations. Mon. Weather. Rev. 142, 4872-4888.

Schüller, K., 2018. Theoretical Basis for Earth Tide Analysis and Prediction. Manual-01-ET34-X-V71, Surin, Thailand, 217 pp., May 2018.

Taguchi, E., Stammer, D., Zahel, W., 2014. Inferring deep ocean tidal energy dissipationfrom the global high-resolution data-assimilative HAMTIDE model. J. Geophys. Res. 119, 4573-4592. https://doi.org/10.1002/2013JC009766.

Warburton, R.J., Goodkind, J.M., 1977. The influence of barometric pressure fluctuations on gravity. Geophys J Roy Astron Soc 48, 281-292.

Wenzel, H.G., 1991. Precise instrumental phase lag determination by the step response method. Bulletin d'Informations des Marées Terrestres 111, 8032-8052.

Zürn, W., Widmer, R., 1995. On noise reduction in vertical seismic records below $2 \mathrm{mHz}$ using local barometric pressure. Geophys. Res. Lett. 22, 3527-3540.

Zürn, W., Wielandt, E., 2007. On the minimum of vertical seismic noise near $3 \mathrm{mHz}$. Geophys. J. Int. 168, 647-658. https://doi.org/10.1111/j.1365-246X.2006.03189.x.

Zürn, W., Meurers, B., 2009. Clear evidence for the sign-reversal of the pressure admit tance to gravity near $3 \mathrm{mHz}$. J. Geodyn. 48 (3-5), 371-377. 